\title{
The Role of the Performance Measurement Systems on Business Process Reengineering: An Empirical Study of Turkish Small and Medium Scaled Manufacturing Firms
}

Cemal Zehir, Erkut Altindag, Ayse Gunsel*

\section{Abstract:}

Today, companies have begun to adopt more flexible structures to adapt to the rapidly changing environment. From the beginning of the 1990 's, companies have needed radical changes to their organizational structures, especially their process methods. Companies need more flexible and faster organizational structures to respond effectively to their customers' growing variety of needs. This new concept of process reengineering has become an appealing alternative for companies.

Reengineering means rebuilding an organization and its entrenched conceptions and design. Competition is intensifying today; reengineering is a convenient method of establishing a new and active structure.

Reengineering tries to specify the role of performance measurement in the reengineering process. The effects of a current performance measurement system, the role of performance measurement, empowerment, integration and long-term strategic alignment are the basic subjects of reengineering. These elements are presented in this paper with positive statistical results. The results of the research and the trends observed are discussed and suggestions are presented for both managers and academicians.

Keywords:

JEL:

DOI: $10.2478 / \mathrm{v} 10033-008-0014-8$

\section{Introduction}

The process of implementing Business Process Reengineering (BPR) is often incomplete and fragmented in the available literature. The solution to this problem might be achieved in two steps. The first step can be considered from two aspects. First, to achieve substantive reengineering performance, a business process should be first analyzed by certain characteristics from a high-level perspective (Teng et al., 1996).

Hammer and Champy (1993) noticed that the commonalities between companies that have chosen radical change to improve performance and those companies that succeed in achieving dramatic results.

This paper will argue some of the main concepts in business process reengineering with the goal of investigating their association with performance measurement systems. First some of the main terms will be discussed and explained.Then the research objectives will be stated followed by the research methodology and hypotheses, the results and conclusions.
*Zehir:
Gebze Institue of Technology,
İstanbul street, no: 101 - GYTE,
Çayırova Gebze/KOCAELI - 41400
e-mail:zehir@gyte.edu.tr
*Altindag:
Gebze Institue of Technology,
İstanbul street, no: 101 - GYTE,
Çayırova Gebze/KOCAELI - 41400
e-mail: ealtindag@gyte.edu.tr
*Gunsel:
Gebze Institue of Technology,
İstanbul street, no: 101 - GYTE,
Çayırova Gebze/KOCAELI - 41400
e-mail: agunsel@gyte.edu.tr 


\section{Business Process Reengineering}

The most successful business book of the last decade, Reengineering the Corporation, is a pioneering work on the most important topic in business today: achieving performance improvements (Hammer and Champy, 1993).

Reengineering is a powerful approach that can bring about radical improvements in business processes. However, the popular management literature has created more myth than practical methodology regarding reengineering. It has relied more heavily on hype than on research, common sense, or the lessons of the past. In this paper, we attempt to "demythologize" some key aspects of reengineering by describing what we have observed in our research and practice. Seven reengineering myths are identified, discussed, and dispelled. By separating rhetoric from reality, we hope to help others to have reasonable expectations for success with their reengineering initiatives (Davenport and Stoddard, 1994).

Reengineering is also known as Business Process Reengineering. Hammer and Champy (1993) define BPR as "the fundamental rethinking and radical redesign of business processes to achieve dramatic improvements in critical contemporary measures of performance, such as cost, quality, service, and speed." Johansson et al. (1993) provide a description of BPR relative to other process-oriented views, "Business Process Reengineering, although a close relative, seeks radical rather than merely continuous improvement. It escalates the efforts of JIT and TQM to make process orientation a strategic tool and a core competence of the organization. BPR concentrates on core business processes, and uses the specific techniques within the JIT and TQM "toolboxes" as enablers, while broadening the process vision."

Reengineering disregards all the assumptions and traditions of the way business has always been done, and instead develops a new, process-centere business organization that achieves a quantum leap forward in performance. To achieve reengineering success, a fresh perspective and approach is required. A clean sheet of paper is taken out and, given what is currently known about customers and their preferences, a new organization is drawn up that will optimize the process of creating satisfied customers. Reengineering is the process by which the organization that exists today is retired and the optimal version of the new organisation is constructed. Reengineering is the opportunity to develop the rules by which business in the future will be conducted rather than being forced to operate by rules imposed by someone else. As such, reengineering underpins every attempt to seize and maintain a true competitive advantage (Hammer and Champy, 1993).

There are many other definitons that are variations of the above, emphasizing different aspects of BPR depending on the application and need (Kuwaiti and Kay, 2000).

Reengineering initiatives typically lead to a business organization with these characteristics:

- Business processes are simplified rather than being made more complex.

- Job descriptions expand and become multi-dimensional - people perform a broader range of tasks.

- People within the organization become empowered as opposed to being controlled.

- The emphasis moves away from the individual and towards the team's achievements.

- The organizational structure is transformed from a hierarchy to a flatter arrangement.

- Professionals become the key focus points for the organization, not the managers.

- The organization becomes aligned with the end-to-end process rather than departments.

- The basis for measurement of performance moves away from activity towards results.

- The role and purpose of the manager changes from supervisor to coach.

- People no longer worry about pleasing the boss. They focus instead on pleasing the customer.

- The organization's value system evolves from being protective to being productive.

All of these definitions clearly recognize that the measurement of performance plays a very important role in the design and implementation of business process reengineering (Kuwaiti and Kay, 2000)

\section{Performance Measurement Systems}

Performance measurement systems are the auditors that in the last decade have increasingly focused on the outputs of management accounting systems. This focus has arisen due to audit practitioners and standard setters advocating that the auditor obtain a more in-depth understanding of a client's business to better aid in risk assessments and audit planning judgments. Hence, audit practitioners have turned to strategic management, especially strategic analysis, for more formal means of understanding a client's business. Strategic management research emphasizes the use of performance measures to determine how successful management is in implementing its strategy, hence leading the auditor to focus on the client's performance measurement system (Salterio et al, 2005). 
Improving competitiveness through performancemeasurement systems can improve competitiveness by meshing the organization's long-term goals with its administrative functions (Stewart and Lockamy 2001).

Measuring performance in the manufacturing sector has been dominated by outdated costing systems and financial reporting required by the legislature and stakeholders (Maskell, 1991). Our performance measurement system employs a balanced scorecard, given its emphasis on management accounting literature and its use by audit firms as a training tool. We predict and find evidence to support the hypothesis that auditors provided with a more extensive strategic analysis employ a broader set of performance measures in making their risk judgments than auditors provided with a less extensive strategic analysis. We also contribute by providing evidence about how differential strategic analysis extensiveness may result in different interpretations of the same outputs from a performance measurement system. (Salterio et al, 2005). Performance measurement systems have to balance a number of dimensions and to play a number of important roles in active business process reengineering to achieve the success of the whole system (Kuwaiti and Kay, 2000).

\section{Empowerment}

Managers indicate a desire to get work done while using less authority; that is, they desire to successfully "empower" employees (Bass et al., 1979). The concept "to empower" means to enable, to allow or to permit, and can be conceived as both self-initiated and initiated by others. Empowerment is the process of enabling workers to set their own work-related goals, make decisions and solve problems within their spheres of responsibility and authority (Litrell, 2006).

For many in Extension, empowerment is the goal we have for our programs and the volunteers, participants, or clients with whom we work. At the core of the concept of empowerment is the idea of power. The possibility of empowerment depends on two things. First, empowerment requires that power can change. If power cannot change, if it is inherent in positions or people, then empowerment is not possible, nor is empowerment conceivable in any meaningful way. In other words, if power can change, then empowerment is possible. Second, the concept of empowerment depends upon the idea that power can expand. This second point reflects our common experiences of power rather than how we think about power (Page and Czuba, 1999).

Power is often related to our ability to make others do what we want, regardless of their own wishes or interests (Weber, 1946). Traditional social science emphasizes power as influence and control, often treating power as a commodity or structure divorced from human action
(Lips, 1991). Conceived in this way, power can be viewed as unchanging or unchangeable. Weber (1946) gives us a key word beyond this limitation by recognizing that power exists within the context of a relationship between people or things. Power does not exist in isolation, nor is it inherent in individuals. By implication, since power is created in relationships, power and power relationships can change. Empowerment as a process of change, then, becomes a meaningful concept.

Empowerment is a construct shared by many disciplines and arenas: community development, psychology, education, economics, and studies of social movements and organizations, among others. How empowerment is understood varies among these perspectives. In recent empowerment literature, the meaning of the term empowerment is often assumed rather than explained or defined. Rappoport (1984) has noted that it is easy to define empowerment by its absence but difficult to define in action as it takes on different forms in different people and contexts. Even defining the concept is subject to debate. Zimmerman (1984) has stated that asserting a single definition of empowerment may make attempts to achieve it formulaic or prescription-like, contradicting the very concept of empowerment.

A common understanding of empowerment is necessary, however, to allow us to know empowerment when we see it in people with whom we are working, and for program evaluation. According to Bailey (1992), how we precisely define empowerment within our projects and programs will depend upon the specific people and context involved.

As a general definition, however, we suggest that empowerment is a multi-dimensional social process that helps people gain control over their own lives. It is a process that fosters power (that is, the capacity to implement) in people, for use in their own lives, their communities, and in their society, by acting on issues that they define as important.

It's suggested that three components of our definition are basic to any understanding of empowerment. Empowerment is multi-dimensional, social, and a process. It is multi-dimensional in that it occurs within sociological, psychological, economic, and other dimensions. Empowerment also occurs at various levels, such as individual, group, and community. Empowerment, by definition, is a social process, since it occurs in relationship to others. Empowerment is a process that is similar to a path or journey, one that develops as we work through it. Other aspects of empowerment may vary according to the specific context and people involved, but these remain constant. In addition, one important implication of this definition of empowerment is that the individual and community are fundamentally connected (Page and Czuba, 1999). 


\section{Integration}

Integration is the degree to which an individual manager's action is harmonious and consistent with that of the other departments, so that the combined action contributes to the added value to the customer and enhancing the overall performance (Kuwaiti and Kay, 2000).

Many factors can influenc the extent of this integration. The literature has identified many such mechanisms. Among the most important are shared vision, culture, goal setting and strategy formulation. For a vision to be realized, it needs to be converted into a process involving the planning and evaluation of performance. Both of these management systems rely on performance information (Sink and Tuttle, 1989; Kaplan and Norton, 1996a; 1996b) Culture has been identified as another integrating mechanism. It needs to be modified and adapted to reflect the organizational context (Kotter and Heskett, 1992).

Today, the companies that have a competitive advantage can use human resources power and its integration to long term strategy formulation (Çelik, 1993).

Integration is an important element in the philosophy. It seeks to weld the organization into a coherent and harmonious entity (Kuwaiti and Kay, 2000).

\section{Method}

\section{Proposed Model and Research Hypotheses}

The conceptual basis for the hypotheses are shown in Fig.2. This framework includes five important variables. The conclusion of the study again pointed to the need for organizations to rethink the way work is being done, and to redesign the processes to achieve an order of magnitude in a number of measures (Hammer and Champy, 1993).

\section{Sample Characteristics}

Hypotheses were tested using 71 small and medium sized manufacturing companies from different industries located throughout the Istanbul and Gebze areas. The target respondents were chiefs and department managers. Responses from more individuals within the company would have given a more complete picture of the firm's situation and behaviour. Excluding cases with missing data, the final sample had 200 usable questionnaires. These questionnaries were collected using mail surveys and face to face interviews.
The questionnaire included five instruments to measure the five variables. Respondents were required to respond to each of the five groups of the questionnaire.

\section{Measures}

All scales are adopted from previous literature (Kuwaiti and Kay, 1997). The first of these variables is the effects of the existing performance measurement system. The instrument used a modified version of the one developed by Dixon et al (1990). The scale used is from 1 to 5 , where 1 indicates low importance or emphasis and 5 denotes high emphasis (Kuwaiti and Kay, 1997). This instrument has 11 statements.

An instrument designed by Hayes (1994) was used to measure the construct of empowerment. This instrument consists of 14 statements. In the analysis, four were eliminated. Respondents were asked to rate the extent to which they agree with each of the statements on a scale from 1 (disagree) to 5 (agree).

The third variable, integration, is a construct represented by 20 statements. Its extent is like an empowerment instrument, except scaled in reverse.

In the analysis of the "long term strategic alignment" instrument 11 statements were used. Respondents were asked to rate their willingness with each statement on a scale from 1 to 5 , where 1 denotes little importance and 5 high importance.

The last variable is the perceived success of performance measurement. A total of 23 statements are represented to respondents about the management's authority (Kuwaiti and Kay, 1997). The scale is from 1 (prohibitive) to 5 (supportive).

Dependent and independent variables will be discussed below.

\section{Measure Validation}

Coefficient alpha estimates (Cronbach's Alpha = $.84 ; .78 ; .87 ; .85 ; .89$, respectively, perceived success of performance measurement, empowerment, integration, long term strategic alignment and existing performance measurement system) show that the measurement scales used in this empirical study are reliable.

\section{Tests of Hypotheses}

Seven hypotheses are examined and tested:

$H_{1}$ : A positive and significant relationship between the effect of the existing performance measurement system and the perceived success of performance measurement. 
The regression analysis result for the effects of the existing performance measurement system on the perceived success of performance measurement indicate that there is a positive and significant relationship between the two variables. Any changes in the effects of the existing performance measurement system may reflect on the perceived success of the performance measurement process.

$\mathrm{H} 2_{\mathrm{a}}$ :There is a positive and significant relationship between the perceived success of performance measurement and empowerment.

$\mathrm{H} 2_{b}$ : There is a positive and significant relationship between the effect of the existing performance measurement system and empowerment.

In the regression analysis conducted to examine the effects of the existing performance measurement system and the perceived success of performance measurement on empowerment, the results show that the effects of the existing performance measurement system have a positive effect on empowerment, but the positive effect of the perceived success of performance measurement on empowerment is not supported.

$\mathrm{H} 3_{\mathrm{a}}$ : There is a positive and significant relationship between the perceived success of performance measurement and integration.

$\mathrm{H} 3_{\mathrm{b}}$ : There is a positive and significant relationship between the effect of the existing performance measurement system and integration.

The regression analysis results for the impacts of the effects of the existing performance measurement system on integration show positive effects on the integration variable. It is hard to say that the same explanation can be used for the effect of the perceived success of performance measurement on integration.

$\mathrm{H} 4_{a}$ : There is a positive and significant relationship between the perceived success of performance measurement and long term strategic alignment.

$\mathrm{H} 4_{b}$ : There is a positive and significant relationship between the effect of the existing performance measurement system and long term strategic alignment.

In the last regression analysis, the hypothesis about a positive and significant relationship between the effect of the existing performance measurement system and long term strategic alignment is accepted.

\section{Discussion}

\section{Limitations and future research directions}

This article has several limitations that should be kept in mind. The extension of the proposed model to other firms would improve the study's overall generalizability. Caution should be taken when applying the results to all organizations, rather than only manufacturing firms. Another potential limitation concerns the multidimensional nature of firm performance. Dealing with the various components of firm performance always presents a challenging set of problems for researchers. National culture, traditions and economic conditions may also influence empowerment and long term strategic alignment.

\section{Conclusion}

In this article, we have focused on the effect of performance measurement systems on business performance and various characteristics of organizations such as empowerment, integration and long term strategic alignment. Performance measurement systems have to provide fast feedback to analyse a firm's performance measurements truthfully.

Managers must make contact with successful workers and adapt them to the business. Empowered employess take more risks and join strategic alliences more often. During the business process reengineering activity, the firm's vision, mission and strategic plan must be upgraded. The subfactors to achieve this are empowerment and the integration of all systems. Organizations wishing to excel in today's global economy expect positive organizational outcomes based on the empowered employee's leadership behavior styles (Wegner, 2004).

In conclusion, this study reveals that manufacturing firms can also increase organizational performance by employing business process reengineering. While maintaining economies of scale, business reengineering can help companies develop personalized products and services (Tai, Huang, 2007). During the business process reengineering, managers must emphasize empowerment to develop their employee's skills, connect all layers and departments smoothly and make new raliable strategic plans. Business reengineering provides a way for manufacturers to effectively respond to the challange of changing environments. Clearly, performance measurement systems on business process reengineering practices have become increasingly more commonplace and therefore require careful empirical analysis to improve our understanding of the outputs of field research. ㄷ. 
Tables and figures

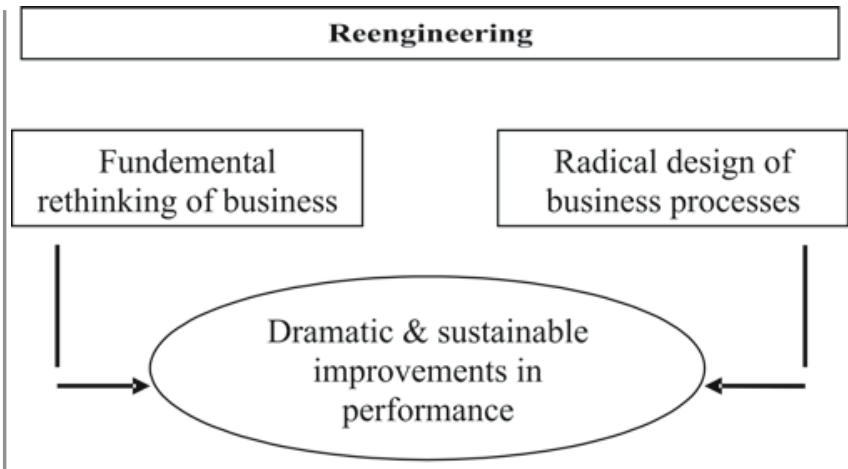

(2)

Figure1. Reengineering process

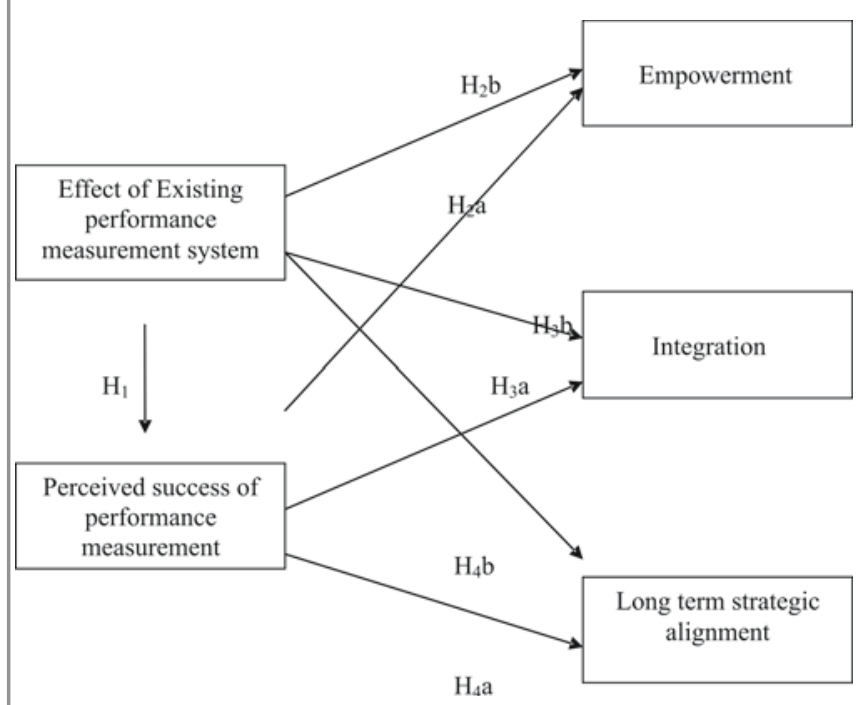

Fig.2: Hypothesized model

\begin{tabular}{|l|c|c|}
\hline Position & Number & Percentage (\%) \\
\hline $\begin{array}{l}\text { Chief/Senior } \\
\text { Chief }\end{array}$ & 118 & 59 \\
\hline $\begin{array}{l}\text { Middle } \\
\text { Level / } \\
\text { Department } \\
\text { Manager }\end{array}$ & 82 & 41 \\
\hline TOTAL & 200 & 100 \\
\hline
\end{tabular}

Table 1 . Sample Characteristics

\begin{tabular}{||l|c||c|}
\hline \multicolumn{1}{||c|}{ VARIABLES } & $\begin{array}{c}\text { Number of } \\
\text { Questions }\end{array}$ & $\begin{array}{c}\text { Coefficient } \\
\text { Alpha }\end{array}$ \\
\hline $\begin{array}{l}\text { 1- Effect of existing } \\
\text { performance measurement } \\
\text { system }\end{array}$ & 11 & 0,89 \\
\hline $\begin{array}{l}\text { 2- Perceived success of } \\
\text { performance measurement }\end{array}$ & 23 & 0,84 \\
\hline 3- Empowerment & 14 & 0,78 \\
\hline \hline 4- Integration & 20 & 0,87 \\
\hline $\begin{array}{l}\text { 5- Long term strategic } \\
\text { alignment }\end{array}$ & 11 & 0,85 \\
\hline
\end{tabular}

Table 2. Output of Reliability Analysis

\begin{tabular}{|l|c|c|c|}
\hline & Standardized $B$ & Sign & Result \\
\hline $\begin{array}{l}\text { Effects of } \\
\text { existing } \\
\text { performance } \\
\text { measurement } \\
\text { system }\end{array}$ & 0,617 & 0,000 & Accepted \\
\hline $\mathrm{F}=171,736$ & \multicolumn{2}{|c|}{$\mathrm{R}^{2}=0,464$} \\
\hline
\end{tabular}

Table 3. Effects of existing performance measurement system on perceived success of performance measurement.

\begin{tabular}{|l|c|c|c|}
\hline & Standardized $ß$ & Sign & Result \\
\hline $\begin{array}{l}\text { perceived } \\
\text { success of } \\
\text { performance } \\
\text { measurement }\end{array}$ & 0,184 & 0,052 & Rejected \\
\hline $\begin{array}{l}\text { effect of existing } \\
\text { performance } \\
\text { measurement } \\
\text { system }\end{array}$ & 0,224 & 0,009 & Accepted \\
\hline $\mathbf{F = 1 6 , 5 9 5}$ & & \\
\hline
\end{tabular}

Table 4. Effects of existing performance measurement system and perceived success of performance measurement on empowerment

\begin{tabular}{|l|c|c|c|}
\hline & Standardized $\beta$ & Sign & Result \\
\hline $\begin{array}{l}\text { perceived } \\
\text { success of } \\
\text { performance } \\
\text { measurement }\end{array}$ & 0,182 & 0,120 & Rejected \\
\hline $\begin{array}{l}\text { effect of } \\
\text { existing } \\
\text { performance } \\
\text { measurement } \\
\text { system }\end{array}$ & 0,406 & 0,000 & Accepted \\
\hline $\mathbf{F = 2 3 , 7 7 9}$ & & \\
\hline
\end{tabular}

Table 5. Effects of existing performance measurement system and perceived success of performance measurement on integration 


\begin{tabular}{||l|c|c|c|}
\hline & Standardized $B$ & Sign & Result \\
\hline $\begin{array}{l}\text { perceived } \\
\text { success of } \\
\text { performance } \\
\text { measurement }\end{array}$ & 7,602 & 0,287 & Rejected \\
\hline $\begin{array}{l}\text { effect of } \\
\text { existing } \\
\text { performance } \\
\text { measurement } \\
\text { system }\end{array}$ & 0,391 & 0,000 & Accepted \\
\hline $\begin{array}{l}|c| \\
\text { F=43,620 }\end{array}$ & $\mathbf{R}^{2}=0,307$ & \\
\hline
\end{tabular}

Table 6. Effects of existing performance measurement system and perceived success of performance measurement on long term strategic alignment

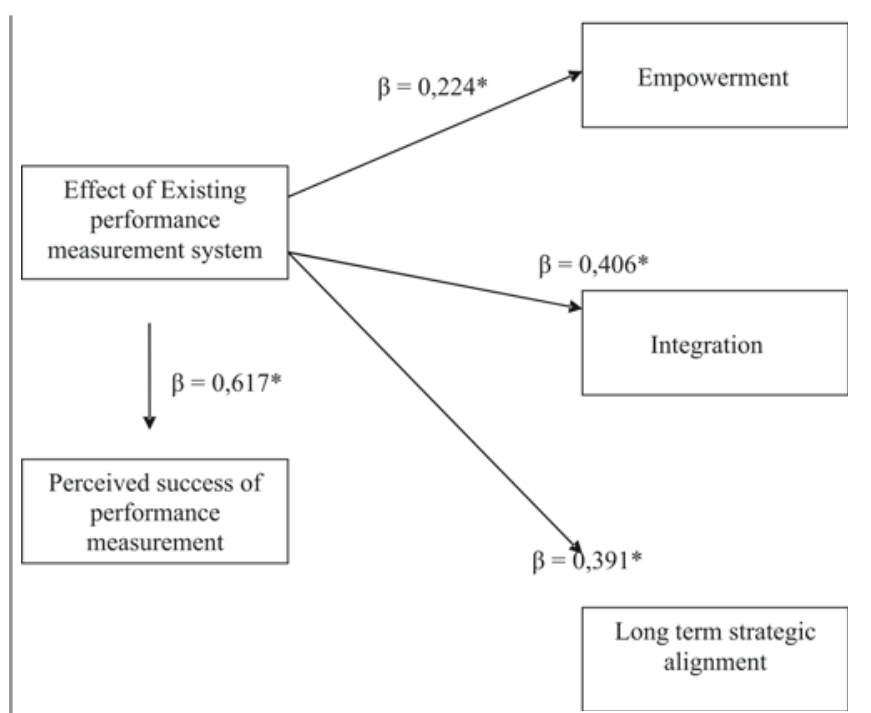

** Significant at 0.01 level

* Significant at 0.05 level

Fig. 3 : Results of Hypotheses tests

\section{References}

Bailey, D. (1992). Using participatory research in community consortia development and evaluation: lessons from the beginning of a story. American Sociologist, 23 (4), 71-82.

Bass, B. M., Burger, P. C., Doktor, R., \& Barrett, G. V. (1979). Assessment of managers: An international Comparison. New York: Free Press.

Çelik, C. (1993). "Kalite Yönetiminde İnsan Faktörü", "Verimlilik Dergisi", MPM Publish, Special Edition (In Turkish)
Davenport, T.H., Stoddard, D.B., (1994), Reengineering: Business Change of Mythic Proportions?, MIS Quarterly, Vol. 18, No. 2, 121-127.

Dıxon, J.R. Ve Arnold, P. ( 1994) "Business Process Reengineering: Improving in New Strategic Directions", California Management Review

Hammer, M., Ve Champy, J. (1993). "Reengineering the coorparation"

Hayes, B. (1996) "How to Measure Empowerment," Quality Progress, February, Vol.27, No:2,

Johansson, H., McHugh, P., Pendlebury, J. and Wheeler, W. (1993), Business Process Reengineering: Break Point Strategies for Market Dominance, John Wiley and Sons, Chichester.

Kaplan, R., Norton, D. (1996) "Using the balanced scorecard as a strategic management system", Harvard Business Review, January/February

Kotter J.P., Heskett J.L., (1992). Corporate culture and performance, Maxwell Macmillan Canada

Kuwaiti, M.E. ve Kay, J. M., "The role of performance measurement in business process re-engineering", International Journal of Operations \& Produciton Management, Vol.20, No:12, 2000.

Lips, H. (1991).Women, men and power. Mountain View, CA: Mayfeld.

Littrell R.F., (2007; 87-110), Influences on employee preferences for empowerment practices by the "ideal manager" in China, International Journal of Intercultural Relations

Maskell, B.H., (1991), Brian Performance measurement for world class manufacturing : a model for American companies, Productivity Press

Page, N, Czuba C. E. (1999) Empowerment: What Is It?, Empowerment:What Is It?, Volume 37 Number 5

Rapport, J. (1984). Studies in empowerment: Introduction to the issue. Prevention in Human Services, $3,1-7$.

Salterio S., W.R. Knechel, N. Kotchetova (July, 2005). Performance Measurement Systems and Strategic Analysis Extensiveness: The Auditor's Usage of Balanced Scorecards and Performance Benchmarks AAA Management Accounting Section 2006 Meeting Paper

Sink, D.S., Tuttle, T.C., (1989; 989 - 999). Planning and measurement in your organization of the future, 
International Journal of Operations \& Production Management, Volume: 18 Issue: $9 / 10$

StewartL.J.,LockamyA.,(2001).Improvingcompetitiveness through performance-measurement systems:

An integrated performance-measurement system can improve competitiveness by meshing the organization's long-term goals with its day-to-day clinical and administrative functions - health care industry, Healthcare Financial Managament

Tai, D. W-S., Huang, C-E., (2007; 296-301). The relationship between electronic business process reengineering and organizational performance in Taiwan, Journal of Academy of Business, Cambridge, Volume: 10, No: 2.

Teng, J.T.C., Grover, V, Fiedler, K.D. (1996). Developing strategic perspectives on business process reengineering from process reconfiguration to organization change, Omega International Journal of Management Science 24 (3), pp. 271-294.

Weber, M. (1946). From Max Weber.H.H.Gerth \& C.W.Mills (Eds.). New York: Oxford University Press.

Wegner, L.L., (2004). Organizational leaders and empowered employees: the relationship between leadership styles, perception of styles, and the impact on organizational outcomes, Capella University.

Zimmerman, M.A. (1984). Taking aim on empowerment research: On the distinction between individual and psychological conceptions.American Journal of Community Psychology, 18(1), 169-177. 